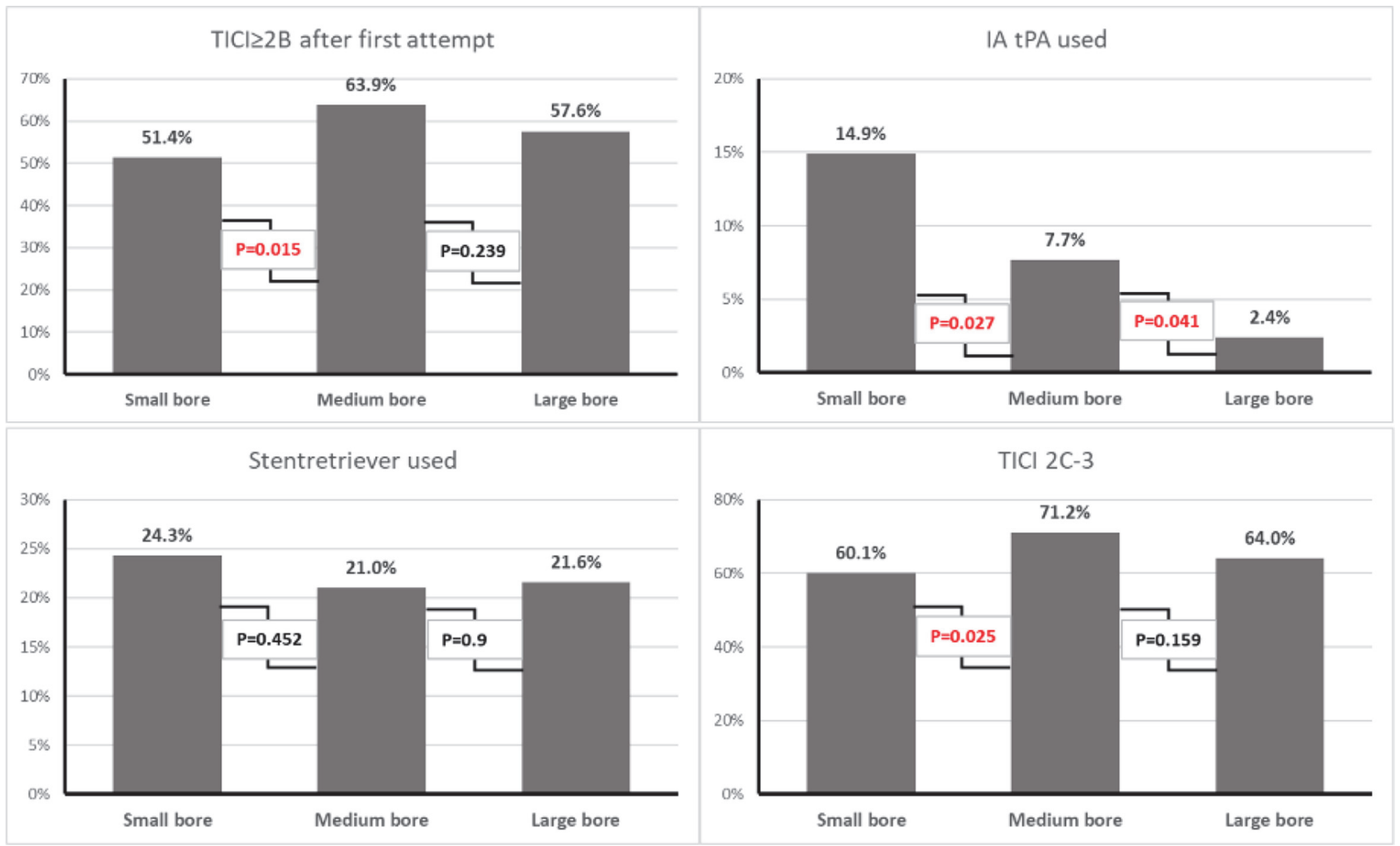

Abstract 0-017 Figure 2

However, large bore catheters did not show significantly better performance results which suggest a plateau effect.

Disclosures S. Al Kasab: None. E. Almallouhi: None. R. Chalhoub: None. A. Alawieh: None. M. Sattur: None. G. Porto: None. E. Bass: None. A. Spiotta: 1; C; Stryker, Penumbra, and Medtronic. 2; C; Stryker, Penumbra, and Terumo.

\section{0-018 THROMBECTOMY OUTCOMES IN PATIENTS WITH LOW ASPECTS TREATED WITHIN 24 HOURS OF SYMPTOMS ONSET: INSIGHTS FROM STAR}

'Z. Hubbard*, 'G. Porto, 'S. Al Kasab, 'E. Almallouhi, ${ }^{2}$ A. Alawieh, ${ }^{3}$ R. De Leacy, ${ }^{4} \mathrm{D}$. Raper, ${ }^{5} \mathrm{~A}$. Rai, ${ }^{6} \mathrm{~T}$. Dumont, ${ }^{7} \mathrm{~S}$. Wolfe, ${ }^{8} \mathrm{P}$. Jabbour, ${ }^{9} \mathrm{C}$. Ogily, ${ }^{10 \mathrm{P}}$. Park, ${ }^{11} \mathrm{M}$. Levitt, ${ }^{12} \mathrm{~A}$. Polifka, ${ }^{13} \mathrm{R}$. Crowley, ${ }^{14} \mathrm{~A}$. Arthur, ${ }^{15} \mathrm{~J}$. Osbun, ${ }^{16} \mathrm{R}$. Crosa, ${ }^{17} \mathrm{I}$. Maier, ${ }^{18} \mathrm{~K}$. Burchiel, ${ }^{2}$ J. Grossberg, ${ }^{19} \mathrm{~S}$. Chowdhry, ${ }^{20} \mathrm{M}$. Mokin, ${ }^{21} \mathrm{C}$. Matouk, ${ }^{22} \mathrm{R}$. Williamson, ${ }^{23} \mathrm{~A}$. Yoo, ${ }^{24} \mathrm{~J}$. Mascitelli, ${ }^{25} \mathrm{P}$. Kan, ${ }^{26} \mathrm{M}$. Psychogios, ${ }^{27} \mathrm{R}$. Starke, ${ }^{1} \mathrm{~A}$. Spiotta. ${ }^{1}$ Medical University of South Carolina, Charleston, SC; ${ }^{2}$ Emory University, Atlanta, GA; ${ }^{3}$ Mount Sinai, New York, NY; ${ }^{4}$ Baylor Medicine Neurosurgery, Houston, TX; ${ }^{5}$ WVU Medicine Neurosurgery, Morgantown, WV; ${ }^{6}$ University of Arizona Neurosurgery, Tuscon, $A Z_{;}{ }^{7}$ Wake Forest Baptist Health Neurosurgery, Lexingon, NC; ${ }^{8}$ Thomas Jefferson University Neurosurgery, Philadelphia, PA; ${ }^{9}$ Beth Israel Hospital-Neurosurgery, Boston, MA; ${ }^{10}$ University of Michigan, Ann Arbor, MI; ${ }^{11}$ UW Neurosurgery, Seattle, WA; ${ }^{12}$ UF Department of Neurosurgery, Gainesville, FL; ${ }^{13}$ RUSH Neurosurgery, Chicago, $\mathrm{LL}_{i}{ }^{14}$ Semmes Murphey Neurosurgeon, Memphis, TN; ${ }^{15}$ Washington University of Saint Louis, St. Louis, MO; ${ }^{16}$ Hospital de Clinicas, Facultad de Medicina, Universidad de la República, Montevideo, Uruguay; ${ }^{17}$ Loma Linda Neurosurgery, Loma Linda, CA; ${ }^{18} \mathrm{OHSU}$ Neurosurgery, Portland, OR; ${ }^{19}$ Northshore, Evanston, $\mathrm{IL}_{i}{ }^{20}$ USF Department of Neurosurgery, Tampa, $\mathrm{FL}_{i}{ }^{21}$ Yale Neurosurgery, New Haven, $C T ;{ }^{22}$ Allegheny Neurosurgery, Pittsburgh, PA; ${ }^{23}$ Texas Stroke Institute, Plano, $T X$; ${ }^{24}$ UT San Antonio, San Antonio, TX; ${ }^{25}$ Medical University of South Carolina, Galveston, $T X_{\text {; }}$ ${ }^{26}$ University Medical Center Göttingen, Göttingen, Germany; ${ }^{27}$ University of Miami Neurosurgery, Miami, FL

10.1136/neurintsurg-2021-SNIS.18
Introduction Outcomes of mechanical thrombectomy (MT) depends largely of achieving reperfusion of a salvageable brain tissue. Patients with poor baseline images were excluded from most clinical trials so the data about their outcomes remain scarce and whether these patients could still benefit from MT remains unknown. In this study, we aim to investigate the safety and efficacy of EVT in patients with large vessel occlusion and large core infarct.

Methods The Stroke Thrombectomy and Aneurysm Registry (STAR) that combined the prospectively maintained databases of 28 thrombectomy-capable stroke centers in the US, Europe, and Asia was interrogated. We included thrombectomy patient presenting with emergent large vessel occlusion within 24 hours and with a large core infarct as defined by Alberta Stroke Program Early CT Score (ASPECTS) < 6. Patients presenting within 6 hours of last known normal (LKN) were considered in the early window and patients presenting after 6 hours were considered in the late window. 90-day outcomes were assessed using modified Rankin scale (mRS)We used a logistic regression model to assess the factors associated with good 90-day outcome in patients in the early and late thrombectomy window.

Results 144 patients were included in this study (table). Median age was 69 and $92(64 \%)$ patients were treated in the early MT window. M1 was the most common site of occlusion (51.4\%) and ADAPT was used in 34.7\%. Median admission NIHSS was 17.5. Successful recanalization (TICI $>2$ b) was achieved in $84.7 \%$ and median procedure time was 54 minutes. sICH hemorrhage was observed in 22 (15.3\%). Regarding 90-day outcome, median mRS was 4, favorable outcome (mRS 0-2) was observed in 41 patients $(28.5 \%)$ and mortality occurred in in 59 (41\%). There was no difference in 90-day functional outcome between patients 
in early and late windows. In patients presenting in the early window, age $(\mathrm{aOR}=0.905, \mathrm{p}=0.0002 ; \mathrm{CI}=0.858-0.954)$ and baseline NIHSS $(\mathrm{aOR}=0.909, \mathrm{p}=0.0423 ; \mathrm{CI}=0.829-0.997)$ were independently associated with 90-day outcome. In patients presenting in the late window, only age $(\mathrm{aOR}=0.934$, $\mathrm{p}=0.0069 ; \quad \mathrm{CI}=0.888-0.981) \quad$ was independently associated with good outcome.

Conclusion More than one in four patients presenting with ASPECTS $<6$ may achieve functional independence at 90-day following MT. Patient age remained the main predictors of 90-day outcome in patients with low ASPECTS in both late and early window.

Disclosures Z. Hubbard: None. G. Porto: None. S. Al Kasab: None. E. Almallouhi: None. A. Alawieh: None. R. De Leacy: None. D. Raper: None. A. Rai: None. T. Dumont: None. S. Wolfe: None. P. Jabbour: None. C. Ogilvy: None. P. Park: None. M. Levitt: None. A. Polifka: None. R. Crowley: None. A. Arthur: None. J. Osbun: None. R. Crosa: None. I. Maier: None. K. Burchiel: None. J. Grossberg: None. S. Chowdhry: None. M. Mokin: None. C. Matouk: None. R. Williamson: None. A. Yoo: None. J. Mascitelli: None. P. Kan: None. M. Psychogios: None. R. Starke: None. A. Spiotta: None.

\section{0-019 INCREASING INNER DIAMETER LEADS TO FASTER THROMBECTOMY WITH ASPIRATION IN ACUTE ISCHEMIC STROKE}

\begin{abstract}
1J Vargas*, ${ }^{2} \mathrm{~S}$ Majidi, ${ }^{3} \mathrm{G}$ Cortez, ${ }^{3} \mathrm{~A}$ Aghaebrahmin, ${ }^{3} \mathrm{E}$ Sauvageau, ${ }^{3} \mathrm{R}$ Hanel, ${ }^{4} \mathrm{H}$ Hawk, ${ }^{5} \mathrm{~S}$ Nimjee, ${ }^{5} \mathrm{~A}$ Zakeri, ${ }^{6} \mathrm{M}$ Mokin, ${ }^{7} \mathrm{C}$ Chen, ${ }^{7} \mathrm{R}$ Kellogg, ${ }^{1} \mathrm{~A}$ Turk, ${ }^{2} \mathrm{R}$ Deleacy, ${ }^{8} \mathrm{~A}$ Siddiqui, ${ }^{9} \mathrm{M}$ Oselkin, ${ }^{9} \mathrm{E}$ Marlin, ${ }^{1} \mathrm{R}$ TUmer, ${ }^{1} \mathrm{I}$ Chaudry, ${ }^{10} \mathrm{~J}$ Milburn. ${ }^{1}$ Prisma Health - Upstate, Greenville, SC; ${ }^{2}$ Neurosurgery, Mount Sinai Health System, New York, NY; ${ }^{3}$ Neurosurgery, Baptist Medical Center, Jacksonville, FL; ${ }^{4}$ Radiology, Erlanger Health System, Chattanooga, $\mathrm{TN}^{\prime}{ }^{5}$ Neurosurgery, Ohio State University, Columbus, $\mathrm{OH} ;{ }^{6}$ Neurosurgery, University of South Florida, Tampa, FL; ${ }^{7}$ Neurosurgery, University of Virginia, Charlottesville, VA; ${ }^{8}$ Neurosurgery, University of Buffalo, Williamsville, NY; ${ }^{9}$ St Luke's University Health Care, Bethlehem, PA; ${ }^{10}$ Radiology, Oschner Health, New Orleans, LA
\end{abstract}

\subsection{6/neurintsurg-2021-SNIS.19}

Background Increasing the distal ID of aspiration catheters has been associated with higher quality and faster thrombectomies, due to a presumed higher rate of complete clot ingestion. We aimed to evaluate the recanalization efficacy of newer generation, larger bore aspiration catheters versus smaller distal ID aspiration catheters in a real world data set.

Methods We performed a multicenter retrospective analysis of consecutive acute ischemic stroke patients with M1 occlusion treated within 24 hours from the time of last known well. Patients were divided into two groups based on the distal inner diameter of the aspiration catheter used for reperfusion: $0.070^{\prime}$ or greater (large) and $0.068^{\prime}$ or smaller sized catheters (small). The primary outcome was the rate of TICI $2 \mathrm{C}$ or better reperfusion. Secondary outcomes included the rate of TICI $2 \mathrm{~B}$ or better reperfusion, rate of recanalization on first pass, and access to successful reperfusion time. All data was selfadjudicated. No outside funding was provided for this analysis.

Results Total of 774 patients with acute M1 occlusion who underwent thrombectomy with an aspiration catheter. Larger bore catheters (with a distal ID of 0.070 ' to 0.074') were used in 421 patients, while 353 patients were treated with small aspiration catheters (distal ID of 0.060 to $0.068^{\prime}$ ). There was no significant difference in the rate of TICI $2 \mathrm{~B}$ or better (94.5 vs $94.3 \%, \mathrm{p}=0.909)$, TICI $2 \mathrm{C}$ or better $(62.1 \%$ vs
$59.5 \%, \mathrm{p}=0.451)$, and TICI 3 recanalization $(47.6 \%$ vs $51.3 \%, p=0.311$ ) between groups. However, there the larger catheter group had a significantly improved rate of first pass TICI 2C or better $(46.8 \%$ vs $38.2 \%, \mathrm{p}=0.017)$, and access time to final recanalization (20.1 minutes vs 23.1 minutes, $\mathrm{p}<0.001)$. Rate of hemorrhage on follow up imaging was significantly higher in the large catheter group (15.3\% vs $10.1 \%$, $\mathrm{p}=0.038)$. The baseline mRS score, admission NIHSS score, and the rate of intravenous thrombolytic therapy were not different between the cohorts. The last known normal to access time was significantly higher in the small catheter group (186 minutes vs 288 minutes, $\mathrm{p}<0.001)$. General anesthesia was used more frequently in the small catheter group $(88.1 \%$ vs $19.1 \%, \mathrm{p}=0.006)$.

Conclusion This multicenter, consecutive real-world experience demonstrates that M1 thrombectomy with a larger distal ID catheter is associated with faster time to recanalization and higher rate of TICI $2 \mathrm{C}$ or better recanalization on first pass, but also with a higher rate of hemorrhage on follow up imaging.

Disclosures J. Vargas: 2; C; Cerenovus. 4; C; Truvic. S. Majidi: None. G. Cortez: None. A. Aghaebrahmin: None. E. Sauvageau: None. R. Hanel: 1; C; Microvention, Stryker. 2; C; Stryker, Medtronic, Cerenovus, Balt, Q’APel. 4; C; Rist. 6; C; MiVI. H. Hawk: None. S. Nimjee: None. A. Zakeri: None. M. Mokin: 2; C; Medtronic, Cerenovus. C. Chen: None. R. Kellogg: None. A. Turk: 2; C; Stryker, Balt, Cerenovus, Medtronic, Q'APel, Imperitive Care. 4; C; Imperitive Care. R. Deleacy: None. A. Siddiqui: 2; C; Imperitive Care, Stryker, Medtronic, Microvention, Penumbra. 4; C; Imperitive Care, Truvic. M. Oselkin: None. E. Marlin: None. R. TUrner: 2; C; Siemens, Cerenovus, Q’APel. 4; C; Q’APel. I. Chaudry: 2; C; Cerenovus, Medtronic, Q'APel. 4; C; Q’APel. J. Milburn: None.

\section{0-020 NOVEL CONE BEAM CT TECHNOLOGY IMPROVES IMAGE QUALITY FOR STROKE ASSESSMENT: A PROSPECTIVE SERIES}

${ }^{1} \mathrm{~N}$ Cancelliere*, ${ }^{2} \mathrm{P}$ Nicholson, ${ }^{3} \mathrm{~F}$ Nijnatten, ${ }^{4} \mathrm{E}$ Hummel, ${ }^{4} \mathrm{P}$ Withagen, ${ }^{4} \mathrm{P}$ van de Haar, ${ }^{2} \mathrm{R}$ Agid, ${ }^{4} \mathrm{~B}$ Hallacoglu, ${ }^{4} \mathrm{M}$ van Vlimmeren, ${ }^{1} \mathrm{~V}$ Mendes Pereira. ${ }^{1}$ Department of Medical Imaging, St. Michael's Hospital, Toronto, ON, Canada; ${ }^{2}$ Department of Medical Imaging, Toronto Western Hospital, Toronto, ON, Canada; ${ }^{3}$ IGT, Philips, Best, Netherlands; ${ }^{4}$ Philips, Best, Netherlands

\subsection{6/neurintsurg-2021-SNIS.20}

Background \& Purpose Time is essential for treatment of acute ischemic stroke (AIS) for patients with large-vessel occlusion (LVO). It is now well established that decreasing the time between stroke-onset to groin-puncture significantly improves functional outcomes for these patients. ${ }^{1}$ One potential method of shortening this time is to by-pass the CT department and bring patients directly to the angiosuite for baseline imaging. However, in order for this to gain mainstream acceptance, the diagnostic quality of cone beam CT (CB-CT) performed in the angiosuite needs to be able to exclude haemorrhages, define the stroke core and ideally demonstrate brain perfusion and collaterals for select patients. We plan to present the recent results of 4 ongoing studies aimed to assess the imaging quality of the latest generation CB-CT scans and technology: 1. Non-contrast circular CB-CT scans; 2. Non-contrast dualaxis CB-CT scans; 3. Contrast-enhanced CB-CT Perfusion 